\title{
Drilling fluid loss control via implementing the FMI and DSI logs to protect environment
}

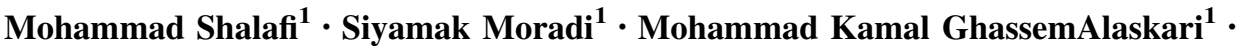 \\ Malihe Sadat Kazemi ${ }^{2}$
}

Received: 12 October 2016/Accepted: 17 October 2016/Published online: 25 October 2016

(C) Springer International Publishing Switzerland 2016

\begin{abstract}
Implementing the drilling fluids in drilling operations is of paramount importance owing to the variety of applications and benefits they provide. Materials added to drilling fluid could cause numerous environmental problems in soil and water resources, and these problems are more pronounced in offshore as compared to land fields. Heavy metals such as mercury, barium, arsenic, lead, and nickel exist in drilling fluid, which bring detrimental damages to the environment. Moreover, heavy metals exist in oil-based muds due to presence of oil where their nickel and vanadium are much greater than other heavy metals. Additive materials and heavy metals existing in drilling fluid could pose irreparable environmental damage if fluid loss into the formation occurs. Regarding to the fact that drilling fluid loss occurs via the open fractures in the wellbore, the main aim of this study is to evaluation of wellbore fractures via implementing the FMI log and fracturing pressure using the slowness of compressional and shear waves. A total of 61 fractures in Dalan formation and 72 fractures in Kangan formation are interpreted and fracturing pressure for these formations, ranges between 8400 and 9450 psi. Implementing the results obtained from this study, drilling fluid loss into the formation and subsequent environmental damage could be prohibited via controlling the pumping pressure and density variation of drilling fluid in accordance with the formation fracturing pressure.
\end{abstract}

Siyamak Moradi

moradi.s@put.ac.ir

1 Department of Petroleum Engineering, Abadan Faculty of Petroleum Engineering (Shahid Tondgooyan), Petroleum University of Technology, Abadan, Iran

2 Technical and Professional University, Tehran, Iran
Keywords Heavy metal · Image log · DSI · FMI · Fracture

\section{Introduction}

The most common fluids implemented in drilling industry are typically categorized into two groups: water-based and oil-based fluids. Chemical additives added to drilling fluids and heavy metals existing in oil-based muds have a lot of environmental impact (Ferrari et al. 2000; Gbadebo et al. 2010). Among these, additives used for shale swelling inhibition and heavy metals such as nickel and cadmium have led to wide number of environmental problems (Bakke et al. 2013). Also, these heavy metals also could be found in subsurface layers, because of heavy minerals deposition at the time of sedimentation (Maria-Ema et al. 2012; Rahman et al. 2012).

In drilling operation, hydrostatic pressure of drilling fluid is higher than formation pressure, thus drilling fluid can enters into open fractures and enters into surrounding environment and cause damage to soil and underground water. A number of studies have been carried out to minimize the damage resulting from drilling fluids where most of them have focused on variation of additives to drilling fluids or use of synthesized drilling muds to minimize the environmental damage; nevertheless, none of these methods have become practically implemented in the industry (Amanullah and Yu 2005; Moslemizadeh et al. 2015; Tehrani et al. 2009; Zheng et al. 2011). Drilling fluid loss occurs mainly through fractures into the formation and these problems are more pronounced in offshore fields as compared to land (Aston et al. 2004; Labenski et al. 2003). In order to provide an initial assessment of the rock fractures, studies are conducted using the common well logs, fluid loss information, and well test analysis. Not all of the 
aforementioned methods possess high resolutions and their assessments are associated with some errors (Zahmatkesh et al. 2015). Implementing the core information significantly assists the study of fractures existing in rock structure; however, coring is not performed in all the intervals mainly owing to their high cost and limited scale (Johns et al. 1993; Zahmatkesh et al. 2015).

FMI is an image log providing high resolution images from the wellbore which are obtained based on the electrical resistivity difference existing among different layers (Khoshbakht et al. 2009; Rajabi et al. 2010). This enables geologists to distinguish small scale phenomena in the wellbore which can be used to help dramatically the field development studies (SUN et al. 2009). One of the main applications of FMI logs is detection of different types of fractures and their relevant parameters such as fracture direction and aperture (Khoshbakht et al. 2009; Rajabi et al. 2010; Tingay et al. 2008). In this study, after processing the raw FMI data, open fractures interpretation has been conducted using FMI log.

In situ stresses are composed of vertical stress, minimum horizontal stress, and maximum horizontal stress components such that the aforementioned in situ stresses are applied at every depth and their estimation could help analyze the dominant tectonic regime in the region (Djurhuus and Aadnøy 2003; Teufel et al. 1991). In general, compressional fractures are generated as a result of improper weight of drilling fluid as well as the tensions surrounding the well which are parallel to maximum horizontal stress. Moreover, fractures existing in the well are directly related to direction of in situ stresses. Moreover, drilling fluid loss is directly related to the density of open fractures inside the rock (Aadnoy and Bell 1998; Djurhuus and Aadnøy 2003). In order to estimate the fracturing pressure, it is highly essential to measure the in situ stresses, formation tensile strength, and pore pressure (Aadnoy and Larsen 1987). One of the methods to evaluate in situ stresses is to use slowness of compressional and shear waves which is a bit complicated for shear waves. Slowness of compressional and shear waves could be estimated using DSI data interpretation (Ougier-Simonin and Zhu 2015; Tellez et al. 2007).

Finally, fracturing pressure could be calculated for different zones via transition time of compressional, shear waves, and density, and substitution of their values in mathematical equations. Formation fracturing and invasion of drilling fluid as an environmentally threatening fact could be obviated using the values necessary for fracturing of different formation members and via implementing a drilling fluid with optimum density.

\section{Study area}

The study was carried out on South Pars gas field, which is the most giant known gas filed in the world. South Pars gas field is located in Persian Gulf, $175 \mathrm{~km}$ from Kish Island and $105 \mathrm{~km}$ from Qatar. Geographical location of the filed is shown in Fig. 1. Kangan and Dalan formations are the major reservoirs of South Pars gas field. Previously studies have divided the Kangan and Dalan formations into four members, which are K1, K2, K3 and K4. The main lithology of Kangan and Dalan formations consist of calcite and dolomite (Aali et al. 2006).

The dominant lithology of $\mathrm{K} 1$ member is calcite, dolomite and anhydritic dolomite and $\mathrm{K} 2$ member is consist of calcite and dolomite. The main dominant lithology of K3 and $\mathrm{K} 4$ consist of calcite and dolomite with some anhydrite intervals. Furthermore, previous studies have shown that, K2 member in Kangan formation and K4 member in Dalan formation are the hydrocarbon bearing zones (Aali et al. 2006; Esrafili-Dizaji and Rahimpour-Bonab 2009).

\section{Data set and methodology}

Due to primary analysis of lithology and fluid saturation, conventional well logs such as gamma ray, neutron, density, photoelectric effect and resistivity logs were corrected. After environmental correction of well logs data, lithology and fluid saturation were evaluated using probabilistic (MULTIMIN) method. By MULTIMIN method, using all available logs data for interpretation of unknowns such as minerals volume and fluid volumes are possible. MULTIMIN method is based on statistics and probability equations. In this study, lithology and fluid saturation in reservoir were interpreted using this method (Hatheway 2005; Rahim and Watson 2015).

Formation Micro Imager (FMI), is one of the imaging tool with four pads, four flaps. Each pads and flaps have 24 bottoms, so FMI tool has 192 bottoms. Image logs depending on the service company and the tool type have specific number of pads. High resolution images of reservoir layers based on their resistivity changes are possible using FMI logs. FMI is the microresistivity imaging tool and it has required conductive drilling fluid (Khoshbakht et al. 2009; Rajabi et al. 2010; SUN et al. 2009). For interpretation of structural features in reservoirs, FMI raw data should be processed. In this study GEOLOG 7.1 software from Paradigm company is used for image processing and interpretation of fractures. The major steps of image processing in GEOLOG 7.1 software are shown in Fig. 2. 


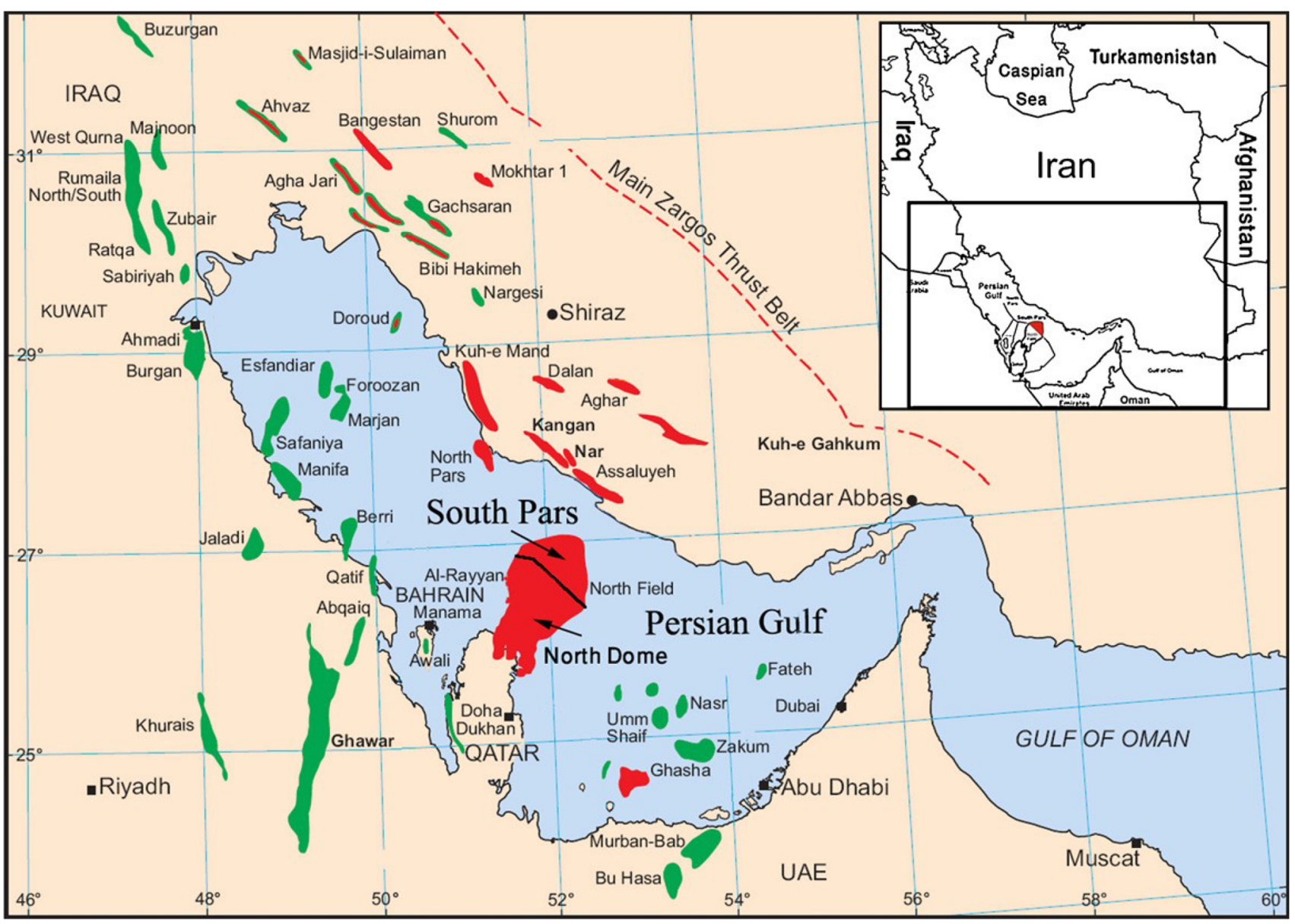

Fig. 1 Geographical location of South Pars gas field in Persian Gulf (Insalaco et al. 2006)

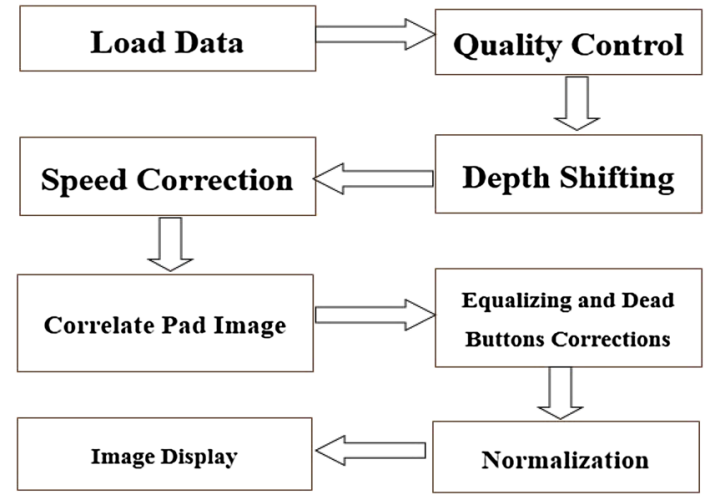

Fig. 2 Major processing steps in GEOLOG software (Poppelreiter et al. 2010)

In this study, from the depth of $2895 \mathrm{~m}$ to the depth of $3280 \mathrm{~m}$, open fractures were interpreted. Quality control of FMI data were done by using cross-lots of accelerometers and magnetometers data. In vertical well, if the tool has rotated while logging, the accelerometer and magnetometer logs should show a circular distribution. Depth matching is essential to correlate the wireline, FMI and DSI logs. Speed correction is used to correct the cable tension and abrupt variations in logging speed. Correlate pad image, is used to corrected saw tooth effects and tries to correlate pad to pad and button to button. Equalizing and dead buttons correction attempts to correct the responses of dead buttons. Normalization is used to provide static and dynamic images of borehole.

Acquisition the slowness of compressional, shear and stoneley waves can be done by using DSI tools. DSI tool consists of transmitter section, receiver section and acquisition cartridge. The transmitter section contains a monopole transmitter and two perpendicular dipole transmitters and receiver section includes eight receiver stations (Chabot et al. 2001; Moatazedian et al. 2011).

In this study DSI log data after quality control were processed in order to obtain the slowness of compressional and shear waves. Due to noise attenuation, time average and frequency filters were applied to raw data. Processing and interpretation of DSI data were done in GEOLOG 7.1.

Compressional and shear waves slownesses were used to calculate elastic moduli. In order to calculate elastic moduli such as shear modulus, young modulus, bulk modulus and 
Poisson's ratio. P-wave and S-wave velocities and density of the earth layers were used. Slowness is the reciprocal of velocity, thus P-wave and $\mathrm{S}$-wave velocities can be calculated from DSI outputs.

The elastic moduli are calculated by the equations below (Harrison 1990; Hudson and Harrison 1997).

$\mu=\rho V_{s}^{2}$

$E=\frac{\rho V_{s}^{2}\left(2 V_{p}^{2}-4 V_{s}^{2}\right)}{\left(V_{p}^{2}-V_{s}^{2}\right)}$

$K=\rho\left(V_{p}^{2}-4 / 3 V_{s}^{2}\right)$

$\theta=\frac{\left(V_{p}^{2}-V_{s}^{2}\right)}{2\left(V_{p}^{2}-V_{s}^{2}\right)}$,

where $V_{p}$ and $V_{s}$ are the velocity of compressional and shear waves, $\rho$ is the density of earth layers, $\mu$ is the shear modulus, $E$ is the young modulus, $\mathrm{K}$ is the bulk modulus and $\theta$ is the Poisson's ratio.

Unconfined compressive strength is the axial compressive stress that a rock can withstand under unconfined condition (Consoli et al. 2010).

The tensile strength is about 0.1 of unconfined compressive strength. Unconfined compressive strength is expressed by the following equation (Militzer and Stoll 1973; Zoback 2010).

$U C S=(7682 / D T)^{1.82} / 145$,

where UCS, is the unconfined compressive strength and DT is the slowness of compressional wave on the base of $\frac{\mu s}{f t}$. Underground reservoir rocks are under stresses and the magnitude of stresses are the function of various factors such as lithology, depth of the formations, pore pressure and tectonics. In situ stresses have has three components and in any depth of the borehole, three stresses are applied which include minimum horizontal stress, maximum horizontal stress and vertical stress. Overburden stress is associated to the density of earth layers and the depth of the formations. Vertical stress is due to due to overburden pressure and can be defined by the following equation (Zoback 2010).

$\delta_{V}=\int_{0}^{z} \rho(Z) g d z \cong \bar{\rho} g z$,

where $g$ is the gravitational acceleration, $\rho$ is the density of the earth layers and z-axis is pointing vertically downward, with $z=0$ corresponding to the earth surface.

In situ stresses have has three components and in any depth of the borehole, three stresses are applied which include minimum horizontal stress, maximum horizontal stress and vertical stress. Minimum horizontal stress and maximum horizontal stress are the essential parameters for wellbore stability modeling. In general, shear fractures occur in the direction of minimum stress and tensile fractures occur in the direction of maximum stress. In order to obtain minimum and maximum horizontal stresses, using elastic moduli of the rock is essential. Minimum and maximum horizontal stresses were calculate by the following equations (Hudson and Harrison 1997; Zoback 2010).

$$
\begin{aligned}
& \sigma_{h}=\frac{\theta}{1-\theta} \sigma_{\theta}+\frac{1-2 \theta}{1-\theta} \alpha P_{p}+E \frac{\varepsilon_{X}}{1-\theta^{2}}+E \frac{\theta z_{y}}{1-\theta^{2}} \\
& \sigma_{H}=\frac{\theta}{1-\theta} \sigma_{\theta}+\frac{1-2 \theta}{1-\theta} \alpha P_{p}+\frac{E \varepsilon_{y}}{1-\theta^{2}}+\frac{\theta E z_{X}}{1-\theta^{2}}
\end{aligned}
$$

where $\sigma_{h}$ is the minimum horizontal stress, $\sigma_{H}$ is the maximum horizontal, $\theta$ is the Poisson's ratio, $\mathrm{E}$ is the young modulus and $P_{p}$ is the pore pressure. In order to calculate pore pressure of the formation, the vertical pressure gradient was calculated based on following equation (Zoback 2010).

$S_{g}=0.433 * \rho_{b}$,

where $\rho_{b}$, is the bulk density of earth layers and $s_{g}$ is the vertical pressure gradient. Finally, pore pressure was measured using following equation (Zoback 2010).

$P_{p g}=s_{g}-\left(s_{g}-p_{n g}\right)\left(\frac{\Delta t_{n}}{\Delta t_{0}}\right)^{3}$,

where $P_{p g}$, is the pore pressure gradient, $s_{g}$ is the vertical pressure gradient, $p_{n g}$ is the normal pressure gradient, $\Delta t_{n}$ is the normal compaction trend and $\Delta t_{0}$ velocity interval velocity observed.

Finally by using of minimum horizontal stresses, maximum horizontal stresses and fracture pressures for all the members of Kangan and Dalan fracture pressure were measured. Fracture pressure can be defined as following equation (Zoback 2010).

$P_{f}=3 \sigma_{h}-\sigma_{H}+T_{s}-P_{p}$,

where $P_{f}$, is the tensile fracture pressure, $\sigma_{h}$ is the minimum horizontal stress, $\sigma_{H}$ is the maximum horizontal stress, $T_{s}$ is the tensile strength and $P_{p}$ is the pore pressure.

Table 1 Effective porosity and water saturation values for Kangan and Dalan formations

\begin{tabular}{llll}
\hline Interval & Depth $(\mathrm{m})$ & Effective porosity $(\%)$ & Water saturation $(\%)$ \\
\hline K1 & $2895-2966$ & 4.5 & 58 \\
K2 & $2966-3010$ & 8.2 & 30 \\
K3 & $3010-3133$ & 2.6 & 67 \\
K4 & $3133-3280$ & 6.6 & 39 \\
\hline
\end{tabular}




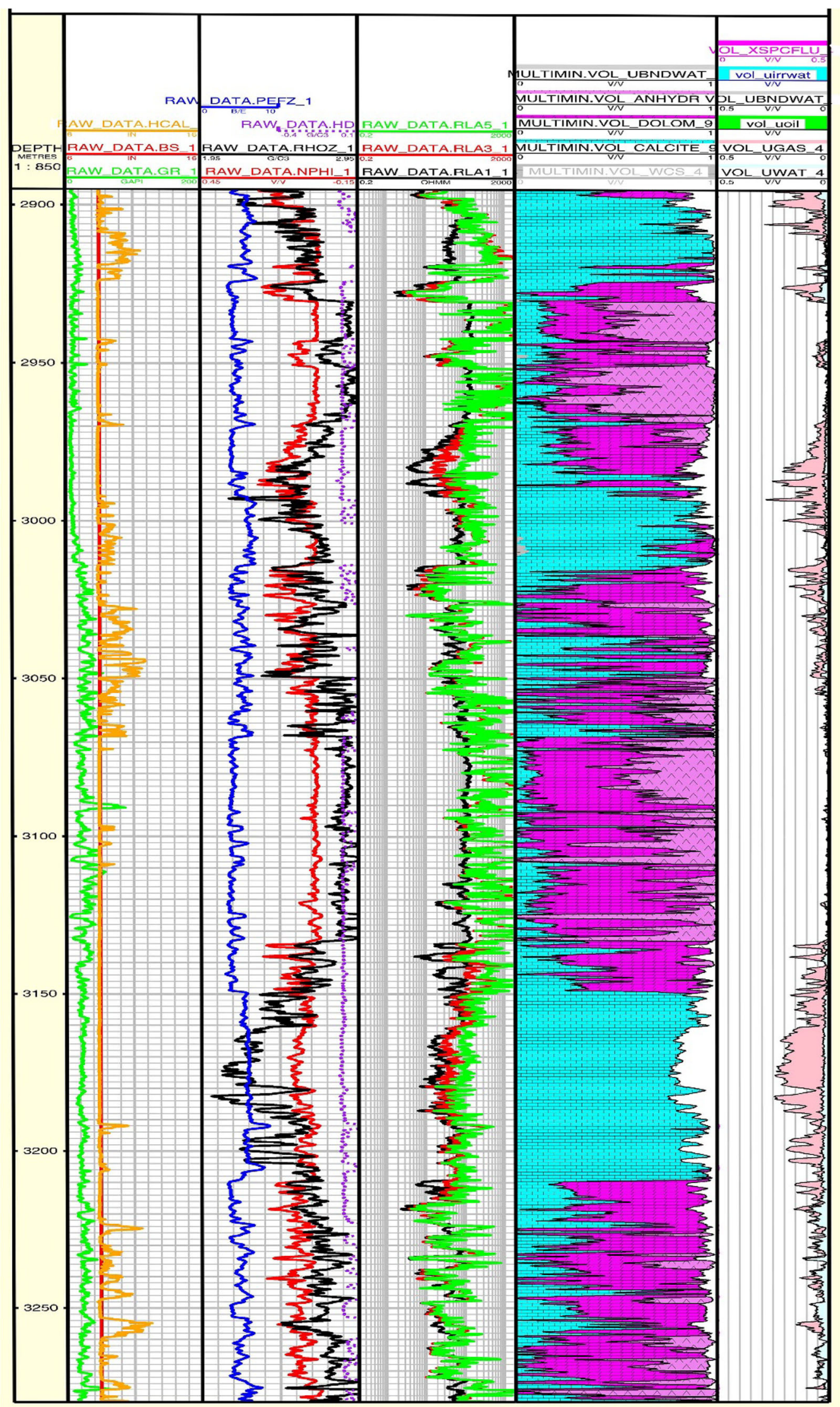

Fig. 3 MULTIMIN interpretation of Kangan and Dalan formations 


\section{Results and discussions}

Depth intervals, effective porosity and water saturation of $\mathrm{K} 1, \mathrm{~K} 2, \mathrm{~K} 3$ and $\mathrm{K} 4$ members are presented in Table 1 . MULTIMIN interpretations is used to interpretation of lithology and fluid saturation of the reservoir. The outputs of MULTIMIN interpretation is shown in Fig. 3. In the first track, bit size, caliper log and gamma ray log are plotted. The gamma ray $\log$ can be used to calculate the presence of hale volume in formation. In this well, the values of gamma ray is not high, thus shale amounts are negligible in K1, $\mathrm{K} 2$, K3 and K4 members. The comparison between caliper $\log$ and bit size, shape of the borehole can be measured; for instance, from the depth of $3026.5 \mathrm{~m}$ to the depth of $3071 \mathrm{~m}$, borehole diameter is larger than bit size. In second track neutron, density, photoelectric effect are plotted. When the separation neutron log is placed one the right side of the density log, the lithology is sandstone and when the separation of density and neutron and density logs are near to zero the lithology is calcite. Resistivity logs are plotted in third track. The outputs of MULTIMIN interpretation, are demonstrated in fourth and fifth tracks. Lithology volumes are plotted in fourth track and fluid saturations are plotted in fifth track. Also Table 1 demonstrates the important parameters of MULTIMIN interpretation.

In general, carbonate rocks have lower porosities compared to sandstones and rock fracturing acts as the main mechanism of creating the reservoir. According to Table 1, K2 section in Kangan formation has a higher porosity compared to K1 section and K4 section in Dalan formation has a higher porosity compared to K3. Furthermore, lower values of water saturation in $\mathrm{K} 2$ and $\mathrm{K} 4$ sections is an indication of higher volumes of hydrocarbon in these zones. Results show that these two zones have suitable potential for being a reservoir. Neutron and density logs could also be implemented for lithology identification; however, presence of light hydrocarbons affects their values which in turn results in their estimated lithology to be unreliable. Dominant lithology in Dalan and Kangan formations is calcite and dolomite. According to Fig. 3, the amount of anhydrite in $\mathrm{K} 2$ and $\mathrm{k} 4$ sections is lower compared to $\mathrm{K} 1$ and $\mathrm{K} 3$ sections which makes them suitable reservoirs, mainly owing to anhydrite lower porosity.

Calcite, dolomite and anhydrite are the dominant lithology of K1, K2, K3 and K4 members. The K2 and K4 members consist of calcite and dolomite with lesser amounts of anhydrite. The lithological variations from calcite to dolomite and anhydrite control the reservoir properties. From the depth of $2972 \mathrm{~m}$ to the depth of $3005 \mathrm{~m}$ in $\mathrm{K} 2$ member, the gas saturation is high. From the depth of $3142.5 \mathrm{~m}$ to the depth of $3208 \mathrm{~m}$ in $\mathrm{K} 4$ member, the lithology is calcite and the gas saturation is high. There is a good correlation between the lithology from MULTIMIN interpretation and core data. Using the MULTIMIN interpretation methodology, lithology and fluid saturations could be obtained with higher accuracy. Excellent accordance observed while comparing the MULTIMIN results to the information obtained from cores.

After processing the FMI log raw data and applying the necessary corrections, static and dynamic images of the FMI $\log$ were evaluated in order to interpret the open fractures directions. In FMI images, black sine waves in represent the open fractures and bright sine waves indicate filled fractures. In addition, amplitude of the sinus shows the fractures inclination.

Figure 4 shows an example of fractures in the well under study. Three fractures in the depth of 2896.1, 296.2 and $2896.3 \mathrm{~m}$ were identified which were also corroborated to core samples. Figure 5, provides a summary of FMI log

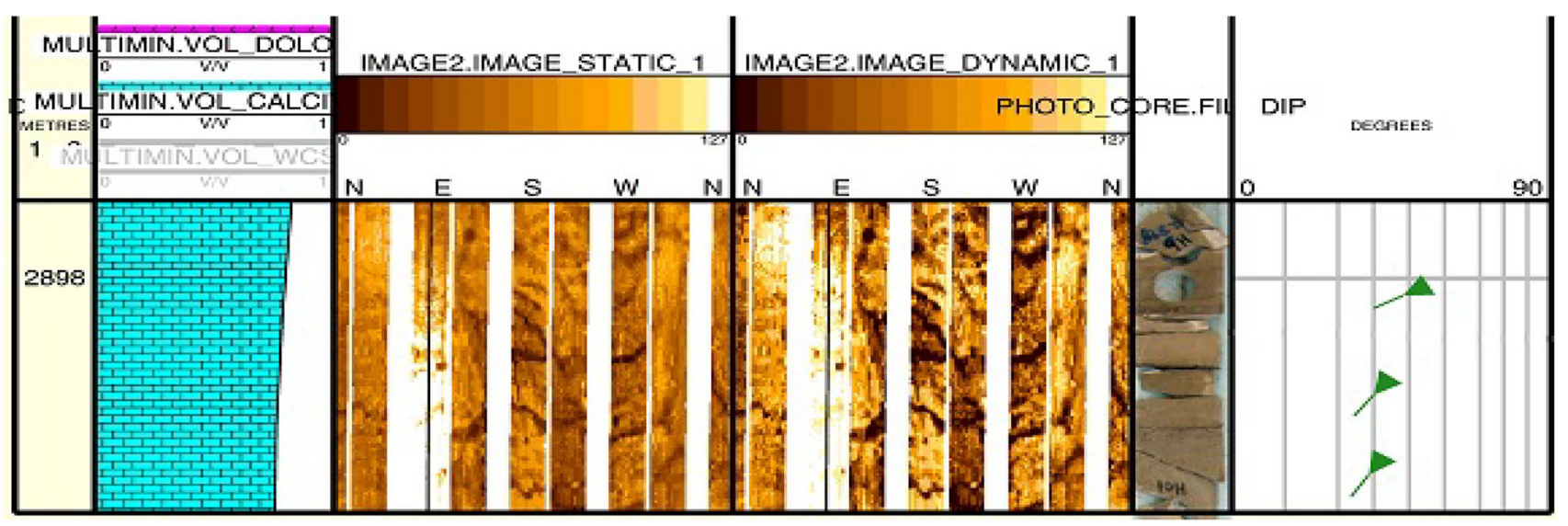

Fig. 4 Interpreted open fractures from FMI $\log$ at the scale of $1 / 8$ 


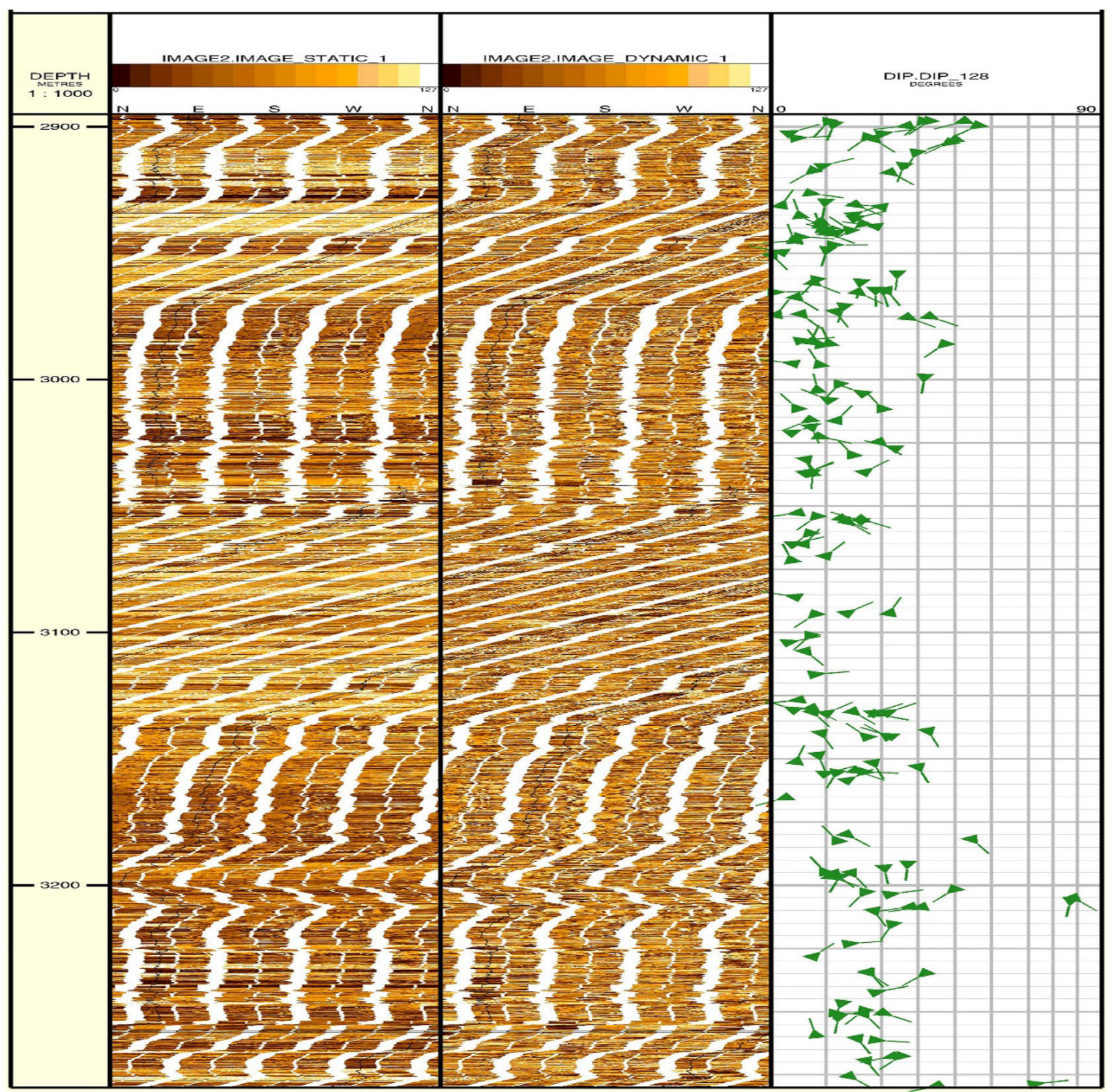

Fig. 5 Interpretation of open fractures in South Pars gas field at the scale of 1/1000

results. In Fig. 5, the first track showing a static image and second track showing a dynamic image. Inclination and azimuth of each fracture in the well are represented using tadpole. As is obvious, fractures existing in the wellbore range from very low to very high inclinations.

A total of 61 open fractures were identified in Kangan formation 48 of which were found to be in $\mathrm{K} 1$ section and 13 of which in K2 section. Similarly, 72 total fractures were identified in Dalan formation 23 of which were found to be in $\mathrm{K} 3$ section and 49 of which in $\mathrm{K} 4$ section. Via interpretation of fractures in the field under study, zones of high fracture density could be identified for fluid loss prognostication. In this study, density of different layers were obtained from density log and slowness of compressional and shear waves were also acquired from processing the DSI data. First, elastic modulus were obtained using Eqs. (1)-(4) and then in situ stresses were calculated in different sections at various depth intervals using the values obtained for slowness of compressional and shear waves and the estimated elastic modulus. Table 2 shows the average value of in situ stresses for different sections of Kangan and Dalan formations.

Comparing the in situ stresses obtained in Dalan and Kangan formations, it could be deduced from the value of 
Table 2 In situ stress values for Kangan and Dalan formations

\begin{tabular}{lllll}
\hline Interval & Depth $(\mathrm{m})$ & $\delta_{V}(\mathrm{MPa})$ & $\sigma_{h}(\mathrm{MPa})$ & $\sigma_{H}(\mathrm{MPa})$ \\
\hline K1 & $2895-2966$ & 51.376 & 39.215 & 46.142 \\
K2 & $2966-3010$ & 53.249 & 39.892 & 47.378 \\
K3 & $3010-3133$ & 54.706 & 40.976 & 47.976 \\
K4 & $3133-3280$ & 56.319 & 41.546 & 48.715 \\
\hline
\end{tabular}

normal stress being greater than the maximum stress as well as the maximum stress being greater than the minimum stress that the tectonic regime in the region under study is normal. By calculating the in situ stresses, pore pressure, and tensile stress, the fracturing pressure was obtained for different layers using the Stabview software. Figure 6, shows different values obtained for fracturing pressure of various sections of the Dalan and Kangan formations.

According to Fig. 6, fracturing pressure for Dalan and Kangan formations ranges between 8400 and 9450 psi. Minimum and the maximum fracturing pressures belong to $\mathrm{K} 1$ and $\mathrm{K} 4$ sections, respectively. Using the values estimated for fracturing pressure of different sections of Kangan and Dalan formations, the pressure required for injection of drilling fluid into the well could be adjusted such that it does not exceed the fracturing pressures of different layers and thereby the fluid loss problems into the formation could be obviated.
Fig. 6 Fracture pressure for the four members of Dalan and Kangan formations

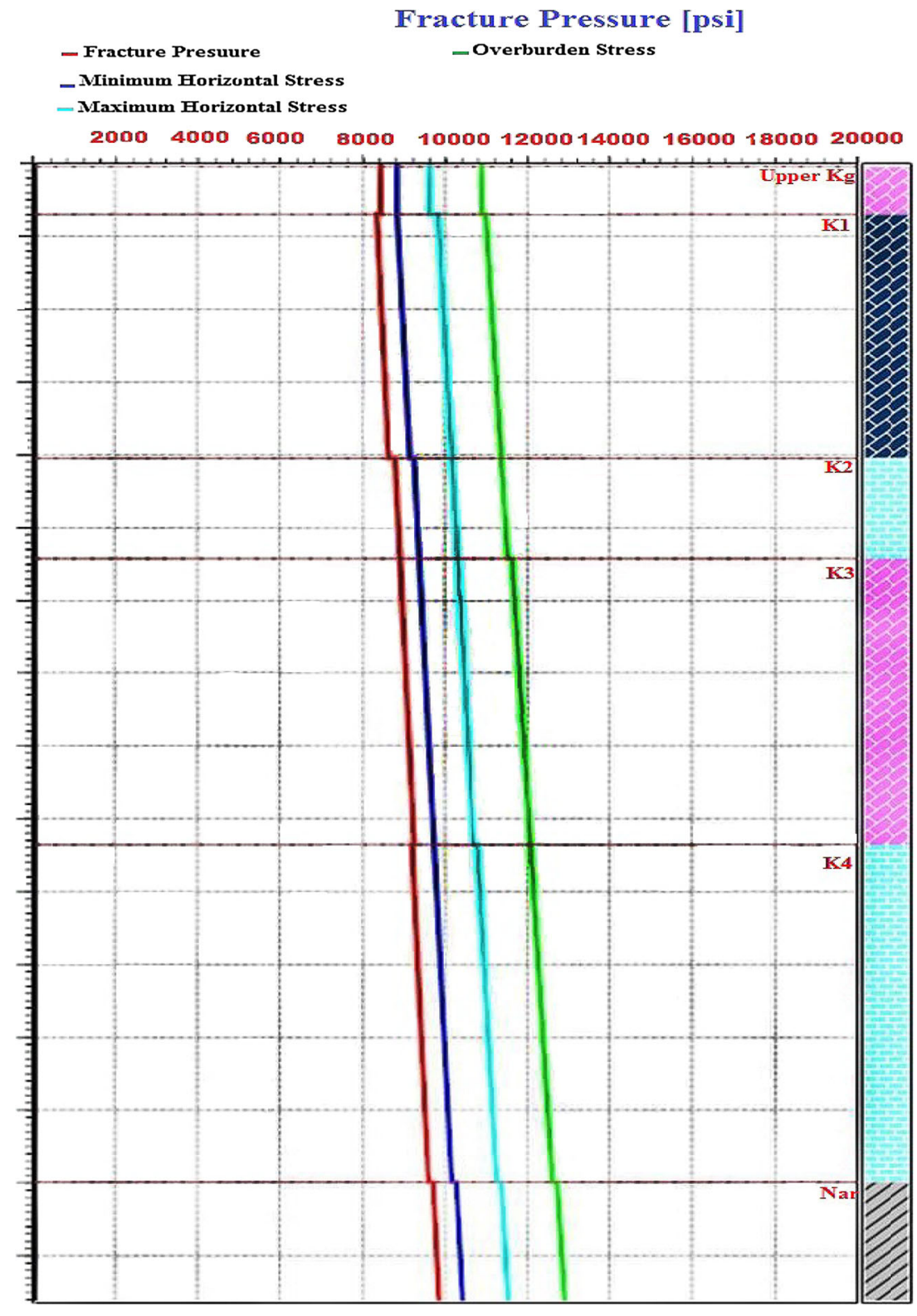




\section{Conclusions}

Based on the results obtained from this study, the lithology of Dalan and Kangan formations as the main reservoir rocks of South Pars oilfield were evaluated using the MULTIMIN interpretation. MULTIMIN interpretation results indicate that the lithology of Dalan and Kangan formations are mostly calcite and dolomite. Moreover, the amount of shale within these formations is negligible and in some sections scattered amounts of anhydrite exists which were identified mostly in $\mathrm{K} 1$ and $\mathrm{K} 3$ sections. Owing to the fact that drilling fluid loss into the formation occurs via the open fractures, these fractures were identified via FMI log processing and interpretation and their inclination and azimuth were indicated using tadpole. Eventually, using the slownesses of compressional and shear waves, elastic modulus were initially estimated and using their values, tensions inside the well were evaluated. According to the values estimated for in situ stresses, tectonic regime of the region was evaluated as normal and values of fracturing pressures for different layers were identified. The value of formation fracturing pressure for Kangan and Dalan formations were evaluated to be in the range of 8400-9450 psi. Fracturing pressure has its minimum value in $\mathrm{K} 1$ section and its maximum value in $\mathrm{K} 3$ section. In this study, fractures inside the wellbore were identified and fracturing pressure for each layer was calculated the results of which could further be implemented for adjusting the drilling fluid injection pressure as well as mud density so as to prevent fluid loss into the formation and the resultant environmental damage.

Acknowledgements This research was supported by Petroleum University of Technology, Iran. The authors are grateful to anonymous reviewers who considerably improved the quality of manuscript.

\section{References}

Aadnoy BS, Bell JS (1998) Classification of drilling-induced fractures and their relationship to in situ stress directions. Log Anal 39(6):27-40

Aadnoy B, Larsen K (1987) Method for fracture gradient prediction for vertical and inclined boreholes. In: SPE Annual Technical Conference and Exhibition, 1987. Society of Petroleum Engineers

Aali J, Rahimpour-Bonab H, Kamali MR (2006) Geochemistry and origin of the world's largest gas field from Persian Gulf. Iran J Petrol Sci Eng 50:161-175

Amanullah M, Yu L (2005) Environment friendly fluid loss additives to protect the marine environment from the detrimental effect of mud additives. J Petrol Sci Eng 48:199-208

Aston M, Alberty M, McLean M, De Jong H, Armagost K (2004) Drilling fluids for wellbore strengthening. In: IADC/SPE Drilling Conference, 2004. Society of Petroleum Engineers
Bakke T, Klungsøyr J, Sanni S (2013) Environmental impacts of produced water and drilling waste discharges from the Norwegian offshore petroleum industry. Mar Environ Res 92:154-169

Chabot L, Henley DC, Brown RJ, Bancroft J (2001) Single-well imaging using the full waveform of an acoustic sonic. In: 2001 SEG Annual Meeting, 2001. Society of Exploration Geophysicists

Consoli NC, Rosa AD, Saldanha RB (2010) Variables governing strength of compacted soil-fly ash-lime mixtures. J Mater Civ Eng 23:432-440

Djurhuus J, Aadnøy B (2003) In situ stress state from inversion of fracturing data from oil wells and borehole image logs. J Petrol Sci Eng 38:121-130

Esrafili-Dizaji B, Rahimpour-Bonab H (2009) Effects of depositional and diagenetic characteristics on carbonate reservoir quality: a case study from the South Pars gas field in the Persian Gulf. Petrol Geosci 15:325-344

Ferrari G, Cecconi F, Xiao L (2000) Drilling Wastes Treatment and Management Practices for Reducing Impact on HSE: ENI/Agip Experiences. In: International Oil and Gas Conference and Exhibition in China, 2000. Society of Petroleum Engineers

Gbadebo A, Taiwo A, Eghele U (2010) Environmental impacts of drilling mud and cutting wastes from the Igbokoda onshore oil wells, Southwestern Nigeria. Indian J Sci Technol 3:504-510

Harrison A (1990) et al. Acquisition and analysis of sonic waveforms from a borehole monopole and dipole source for the determination of compressional and shear speeds and their relation to rock mechanical properties and surface seismic data. In: SPE Annual Technical Conference and Exhibition, 1990. Society of Petroleum Engineers

Hatheway AW (2005) Field Methods for Geologists and Hydrogeologists. Environ Eng Geosci 11:178-179

Hudson JA, Harrison JP (1997) In situ stress. In: Engineering Rock Mechanics. Pergamon Oxford, pp 41-69. doi:http://dx.doi.org/ 10.1016/B978-008043864-1/50005-7

Insalaco E et al (2006) Upper Dalan Member and Kangan Formation between the Zagros Mountains and offshore Fars, Iran: depositional system, biostratigraphy and stratigraphic architecture. GEOARABIA-MANAMA 11:75

Johns RA, Steude JS, Castanier LM, Roberts PV (1993) Nondestructive measurements of fracture aperture in crystalline rock cores using X ray computed tomography. J Geophys Res Solid Earth 98:1889-1900

Khoshbakht F, Memarian H, Mohammadnia M (2009) Comparison of Asmari Pabdeh and Gurpi formation's fractures, derived from image log. J Petrol Sci Eng 67:65-74

Labenski F, Reid P, Santos H (2003) Drilling fluids approaches for control of wellbore instability in fractured formations. In: SPE/ IADC Middle East Drilling Technology Conference and Exhibition, 2003. Society of Petroleum Engineers

Maria-Ema FC, Gabriel L, Valentin N (2012) The assessment of heavy metals concentration in Bacau city soil: Necessity and working methods. J Eng Stud Res 18(1):80-95

Militzer M, Stoll R (1973) Einige Beitrageder geophysics zur primadatenerfassung im Bergbau Neue Bergbautechnik. Lipzig 3:21-25

Moatazedian I, Rahimpour-Bonab H, Kadkhodaie-Ilkhchi A, Rajoli M (2011) Prediction of shear and Compressional Wave Velocities from petrophysical data utilizing genetic algorithms technique: A case study in Hendijan and Abuzar fields located in Persian Gulf. Geopersia 1:1-17

Moslemizadeh A, Shadizadeh SR, Moomenie M (2015) Experimental investigation of the effect of henna extract on the swelling of sodium bentonite in aqueous solution. Appl Clay Sci 105:78-88 
Ougier-Simonin A, Zhu W (2015) Effect of pore pressure buildup on slowness of rupture propagation. J Geophys Res Solid Earth 120:7966-7985

Poppelreiter M, Garcia-Carballido C, Kraaijveld M (2010) Dipmeter and borehole image log technology: AAPG Memoir, vol 92. AAPG, Tulsa

Rahim N, Watson N (2015) Determination of Duvernay Formation Reservoir Properties through Probabilistic Petrophysical Analysis calibrated to Core Studies. Submission (334S0123) Geoconvention. pp 4-8

Rahman SH, Khanam D, Adyel TM, Islam MS, Ahsan MA, Akbor MA (2012) Assessment of heavy metal contamination of agricultural soil around Dhaka Export Processing Zone (DEPZ), Bangladesh: implication of seasonal variation and indices. Appl Sci 2:584-601

Rajabi M, Sherkati S, Bohloli B, Tingay M (2010) Subsurface fracture analysis and determination of in situ stress direction using FMI logs: An example from the Santonian carbonates (Ilam Formation) in the Abadan Plain, Iran. Tectonophysics 492:192-200

Sun LP, Shou H, Zhao XL, Li P (2009) Sedimentary Facies Identification Based on FMI Imaging Logging Data [J]. Well Logging Technol 4:018

Tehrani A, Young S, Gerrard D, Fernandez J (2009) Environmentally friendly water based fluid for HT/HP drilling. In: SPE
International Symposium on Oilfield Chemistry, 2009. Society of Petroleum Engineers

Tellez OM, Casadiego A, Castellanos JE, Lopez ER, Sorenson F, Kessler CW, Torne JP (2007) Application of Dipole Sonic To Evaluate Hydraulic Fracturing. In: International Oil Conference and Exhibition in Mexico, 2007. Society of Petroleum Engineers

Teufel LW, Rhett DW, Farrell HE (1991) Effect of reservoir depletion and pore pressure drawdown on in situ stress and deformation in the Ekofisk field, North Sea. In: The 32nd US Symposium on Rock Mechanics (USRMS), 1991. American Rock Mechanics Association

Tingay M, Reinecker J, Müller B (2008) Borehole breakout and drilling-induced fracture analysis from image logs World Stress Map Project. pp 1-8

Zahmatkesh I, Aghli G, Mohammadian R (2015) Systematic fractures analysis using image logs and complementary methods in the Marun Oilfield. SW Iran Geopersia 5:139-150

Zheng J, Wang J, Musa O, Farrar D, Cockcroft B, Robinson A, Gibbison R (2011) Innovative Chemistry for Drilling Fluid Additives. In: SPE Middle East Oil and Gas Show and Conference, 2011. Society of Petroleum Engineers

Zoback MD (2010) Reservoir geomechanics. Cambridge University Press, Cambridge 